\title{
Outcome of Tuberculosis Control Program in Red Sea State, Sudan
}

\author{
Bashir Abdrhman Bashir ${ }^{1, *}$, Yousif Mohammed Saeed ${ }^{2}$ \\ ${ }^{1}$ Medical Laboratory Sciences Division, Port Sudan Ahlia College, Port Sudan, Sudan \\ ${ }^{2}$ Consultant Chest Physician, Port Sudan Teaching Hospital, Port Sudan, Sudan
}

Email address:

bashirbashir17@hotmail.com (B. A. Bashir)

*Corresponding author

\section{To cite this article:}

Bashir Abdrhman Bashir, Yousif Mohammed Saeed. Outcome of Tuberculosis Control Program in Red Sea State, Sudan. American Journal of Internal Medicine. Vol. 5, No. 5, 2017, pp. 79-82. doi: 10.11648/j.ajim.20170505.13

Received: March 2, 2017; Accepted: March 23, 2017; Published: October 23, 2017

\begin{abstract}
Tuberculosis (TB) is an endemic disease in Red Sea State. Efforts to control this disease started in 1996 with the establishment of a national tuberculosis control committee. Field application of a national tuberculosis program (NTP) was implemented in Port Sudan by the ministry of health, according to the guidelines of the WHO. A retrospective cross-sectional study was conducted to evaluate the outcome of tuberculosis control after the application of this program since 2002 to 2010. The active TB cases admitted and treated in Red Sea tuberculosis diagnostic center were studied. The outcome of control was evaluated, and comparison was made between the years 2002 to 2010.12506 subjects were enrolled in this study. 8337 (66.7\%) were males and $4169(33.3 \%)$ were females. The ages ranged between $14-76$ years. The total number of TB cases were decreased by $61 \%$ (from 1803 in 2002 to 1100 in 2010). The total Pulmonary TB (PTB) positive cases were reduced from $579(32 \%)$ cases in 2002 to $240(22 \%)$ cases in 2010. Default rate decreased in $2002(11.9 \%)$ and increased in $2010(16.7 \%)$. However, there was no substantial improvement in the cure rate, but inversely increased the default rate and death rate $(16.7 \%$ and $9.6 \%$ respectively). The study demonstrated a positive correlation of mortality rate with the default rate $(\mathrm{P}<0.023)$. Accordingly, the overall outcome of the application of the NTP was relatively satisfactory. A recommendation for speedy improve the infrastructure accompanied by supporting material of the health care system to create a suitable successful program is essential.
\end{abstract}

Keywords: Tuberculosis, Outcome, Red Sea State, TB Control, Sudan

\section{Introduction}

Tuberculosis (TB) is a major public health problem in Red Sea State (Port Sudan), Sudan. The pulmonary type is the most important form of tuberculosis, continues to be one of the widest spread infectious diseases [1]. Sudan is the largest country on the African continent, covering 2.5 million $\mathrm{km}^{2}$ with a current estimated population of approximately 45 million, $42 \%$ of whom are believed to be under the age of 15 years [2]. The population is culturally and ethnically diverse with several hundred tribal groupings speaking over 130 languages [3]. During 2010 an estimated $40 \%$ of the people lived in an urbanized environment [2]. It is a poor country and gross national income per capita was less than two thousand international dollars during 2009 with a life expectancy at birth of 58 years [4]. The country has been severely affected by war, famine and flood in recent decades and has a large population of internally displaced persons [5]. It has a high burden of tuberculosis (TB) with a prevalence of 209 cases per 100,000 of the population and 50,000 incident cases during 2009 [6]. The estimated adult HIV prevalence of $1.5 \%$ remains lower than that of its African neighbors to the south and a report from 2002 suggested $4 \%$ of tuberculosis patients were co-infected with HIV [5]. The global estimate of extra pulmonary tuberculosis ranged from $17 \%$ to $52 \%$ of all cases of TB [6]. Sudan holds $8-11 \%$ of the TB burden in the eastern Mediterranean region [7]. In spite of this, there is little published data regarding extra pulmonary TB [8]. The situation of Port Sudan does not differ from another part of the Sudan. However, specific factors which predispose of pulmonary TB (PTB) such as poor socio-economic status, 
high prevalence of malnutrition and infectious diseases, poverty, illiteracy, movement of population (in summer), refugees camps, political instability to some extent, customs and habits (denying infection with TB), and low coverage of Bcilli Chalmette Guerin (BCG) vaccination with limited access to medical facilities still play an important role in increasing incidence rate of TB in Port Sudan $[9,10]$. The international Union against tuberculosis and Lung diseases, The World Health Organization (WHO), Norwegian Heart and Lung disease (LHL), German Leprosy and TB relief Association (GLRA) and Federal Ministry of Health (FMOH) signed a contract for cooperation and financial and technical assistance for TB control in Sudan [9]. The FMOH fully adopted (according to WHO guidelines [10]). Tuberculosis care and treatment is provided by the National Tuberculosis Control Program under the auspices of the Ministry of Health and also by the private sector. TB treatment in the private sector is not regulated [11]. The aim of the present study was to find out the outcome of the national tuberculosis control program in Red Sea State.

\section{Patients and Methods}

\subsection{Study Criteria}

In this retrospective cross-sectional study, all the cases with active pulmonary and extra pulmonary TB admitted to the NTP from 2002 to 2010 were included in this study. The type of TB and associated conditions of the disease were recorded. Diagnosis was made according to the WHO criteria for active TB in pulmonary and extra pulmonary cases [12] Outcome of the management of the disease was evaluated by cure rate, completion of therapy, treatment failure, relapse, default rate and death (mortality rate). All patients were treated with the shorter-course chemotherapy of rifampicin and isoniazid for six months, and Pyrazinamide and Ethambutol in the first two months [13]. The NTP required an assignment of a coordinator in each district. All TB cases were reported to this coordinator, who initiated a special record for each case, which was updated frequently with follow-up data, according to the WHO recommendations [12]. After completion of the drug treatment, patients were asked to return for follow-up visits every six months for two years so as to detect any relapse. A default system was applied when a patient missed a clinic appointment. This included involvement of a social worker or health assistant, and every effort was made to bring the patient back to the clinic for regular monthly follow-up and collection of drug prescription. For the purpose of a uniform definition were adopted [7]:

\subsubsection{Pulmonary TB, Smear-Positive}

A patient with at least one or two sputum specimens which were positive for Acid fast bacilli (AFB) by microscopy, and chest radiographic abnormalities consistent with active pulmonary $\mathrm{TB}$, or a patient with only one sputum specimen which was positive for AFB by microscopy, and a culture positive for mycobacterium tuberculosis.

\subsubsection{Pulmonary TB, Smear-Negative}

A patient with symptoms suggestive for $\mathrm{TB}$, with at least two sputum specimens which were negative for AFB by microscopy, and with chest radiographic abnormalities consistent with active pulmonary TB (including interstitial or miliary abnormal images), or a patient with at least two sputum specimens negative for AFB by microscopy, and a culture positive for mycobacterium tuberculosis, or a patient with two sets of at least two sputum specimens taken at least two weeks apart, and which were negative for AFB by microscopy, and radiographic abnormalities consistent with pulmonary TB and lack of clinical response to one week of broad-spectrum antibiotic.

\subsubsection{Extra Pulmonary TB}

A patient with TB of organ rather than the lung. Pleurisy and mediastinal lymphadenopathy are classified as extra pulmonary TB.

\subsubsection{New Case}

A patient who has never taken anti-TB drugs for more than one month.

\subsubsection{Relapse}

A TB patient who previously received treatment and was declared cured, and has once again developed smear-positive pulmonary TB.

\subsubsection{Treatment Failure}

A TB patient who, while on treatment remained smearpositive; or once more become smear-positive at the fifth month or later during the course of treatment, or one who was initially smeared-negative before starting treatment and become smear-positive after the second month of treatment.

\subsubsection{Return After Interruption (Default)}

A patient who completed at least one month of treatment and returned after at least two months' interruption of treatment.

\subsubsection{Chronic Case}

A patient who remained smear sputum-positive after completing directly observed re-treatment regimen.

\subsection{Statistical Analysis}

Data were analyzed using a Computer Statistical Package for Social Sciences (SPSS) program version 20 (IBN. Chicago, USA). Chi-squared and correlation bivariate tests were used for statistical analysis. $P$-value less than 0.05 were considered significant.

\subsection{Ethical Considerations}

This study received ethical approval from the Research Committee at the Ministry of Health of Red Sea State.

\section{Results}

A total of 12506 patients with TB were enrolled in this 
study, 8337 (66.7\%) were males and 4169 (33.3\%) were females. The ages ranged between $14-76$ years (mean 37 years). The study, including 3518 (28.1\%) with positive PTB sputum smear, 2184 (17.5\%) with negative PTB sputum smear, but culture positive for mycobacterium tuberculosis, $530(4.2 \%)$ with relapse and $6274(50.2 \%)$ with extra pulmonary TB (Table 1). Table 1 shows the decrease in tuberculosis cases over the years in the period $(2002-2010)$. In 2002 pulmonary TB cases made up only $32.1 \%$ (579) of all TB cases, and this ratio relatively changed over the following seven years, and then it decreased to $22 \%$ (240) in 2010. The PTB negative cases started with $16 \%$ and noticeably increased in 2007 where the value reached $22.1 \%$ and decreased to $19 \%$ for approximately the following three years.

The extra-PTB cases steadily increased over the study period. The total numbers of cases increased only in the first three years $(2002,2003$, and 2004). There was no change in the relapse rate, but was only slightly decreased in 2008 2009 (3.3\% - 2.8\% respectively). The outcome of treatment of tuberculosis cases is shown in (Table 2). The standard sixmonth short course regimen gave only a $58 \%$ in 2002 and then increased to $71 \%$ in $2006-2007$ and decline to $55 \%$ in 2010 proven cure rate, with at least three negative running sputum smear tests. Treatment failure (continued positive smear despite prolonged therapy) occurred in only a little number $(0.0 \%-5.8 \%)$. Default rate slightly start increasing from 2002 to $2010(11.9 \%-16.7 \%)$ respectively. There was a positive correlation between default rates and the completion therapy $(\mathrm{P}<0.042)$. However, the mortality rate increased in $2010(9.6 \%)$. A positive correlation of mortality rate was noted with the default rate $(\mathrm{P}<0.023)$.

Table 1. Types of TB cases admitted to Port Sudan teaching hospital-Chest department between 2002 - 2010.

\begin{tabular}{|c|c|c|c|c|c|}
\hline Years/Type & PTB +ve & PTB -ve & Extra PTB & Relapse & Total \\
\hline 2002 & $579(32 \%)$ & $291(16 \%)$ & $848(47 \%)$ & $85(4.7 \%)$ & $1803(14.4 \%)$ \\
\hline 2003 & $478(28 \%)$ & $206(12 \%)$ & $933(55 \%)$ & $75(4.4 \%)$ & $1692(13.5 \%)$ \\
\hline 2004 & $448(31 \%)$ & $224(16 \%)$ & $689(48 \%)$ & $69(4.8 \%)$ & $1430(11.4 \%)$ \\
\hline 2005 & $452(33 \%)$ & $212(15 \%)$ & $658(48 \%)$ & $61(4.4 \%)$ & $1383(11.1 \%)$ \\
\hline 2006 & $396(29 \%)$ & $287(21 \%)$ & $630(46 \%)$ & $68(4.8 \%)$ & $1381(11.0 \%)$ \\
\hline 2007 & $340(26 \%)$ & $292(22 \%)$ & $630(46 \%)$ & $48(3.7 \%)$ & $1310(10.5 \%)$ \\
\hline 2009 & $246(23 \%)$ & $202(19 \%)$ & $589(55 \%)$ & $30(2.8 \%)$ & 1067 (8.5\%) \\
\hline 2010 & $240(22 \%)$ & $210(19 \%)$ & $600(55 \%)$ & $50(4.6 \%)$ & $1100(8.9 \%)$ \\
\hline Total & $3518(28.1 \%)$ & $2184(17.5 \%)$ & $6274(50.2 \%)$ & $530(4.2 \%)$ & $12506(100 \%)$ \\
\hline
\end{tabular}

Table 2. Outcome of pulmonary TB positive cases between $2002-2010$.

\begin{tabular}{|c|c|c|c|c|c|c|c|c|c|}
\hline $\begin{array}{l}\text { Years } \\
\text { Outcome }\end{array}$ & $\begin{array}{l}2002 \\
\text { No. \% } \\
\end{array}$ & $\begin{array}{l}2003 \\
\text { No. \% } \\
\end{array}$ & $\begin{array}{l}2004 \\
\text { No. \% } \\
\end{array}$ & $\begin{array}{l}2005 \\
\text { No. \% } \\
\end{array}$ & $\begin{array}{l}2006 \\
\text { No. \% } \\
\end{array}$ & $\begin{array}{l}2007 \\
\text { No. \% } \\
\end{array}$ & $\begin{array}{l}2008 \\
\text { No. \% } \\
\end{array}$ & $\begin{array}{l}2009 \\
\text { No. } \% \\
\end{array}$ & $\begin{array}{l}2010 \\
\text { No. \% } \\
\end{array}$ \\
\hline Cured & $335(58 \%)$ & $303(63 \%)$ & $312(69.6 \%)$ & $320(70.8 \%)$ & $284(71.7 \%)$ & $243(71.5 \%)$ & $230(67.9 \%)$ & $124(50.4 \%)$ & $133(55.4 \%)$ \\
\hline Complete therapy & $134(23 \%)$ & $64(13.4 \%)$ & $80(17.9 \%)$ & $59(13.1 \%)$ & $51(12.9 \%)$ & $49(14.4 \%)$ & $57(16.8 \%)$ & $55(22.4 \%)$ & $30(12.5 \%)$ \\
\hline Treatment failure & $8(1.4 \%)$ & $20(4.2 \%)$ & $7(1.6 \%)$ & $9(1.9 \%)$ & $5(1.3 \%)$ & $10(2.9 \%)$ & $0(0.0 \%)$ & $5(2.0 \%)$ & $14(5.8 \%)$ \\
\hline Default & $69(11.9 \%)$ & $59(12.3 \%)$ & $32(7.1 \%)$ & $40(8.9 \%)$ & $40(10.1 \%)$ & $29(8.5 \%)$ & $42(12.4 \%)$ & $42(17.1 \%)$ & $40(16.7 \%)$ \\
\hline Death & $33(5.7 \%)$ & $30(6.7 \%)$ & $24(5.4 \%)$ & $24(5.3 \%)$ & $16(4.0 \%)$ & $9(2.7)$ & $10(2.9 \%)$ & $20(8.1 \%)$ & $23(9.6 \%)$ \\
\hline All cases & 579 & 478 & 448 & 452 & 396 & 340 & 339 & 246 & 240 \\
\hline
\end{tabular}

\section{Discussion}

Tuberculosis is a major public health problem that represents a challenge in Red Sea State. In this study, the proven cure rate was steadily decreased from $58 \%$ in 2002 to $55 \%$ in 2010 , and the default rate and treatment failure slightly increased, and the total number of tuberculosis cases was actually decreased. The proportion of extra-pulmonary TB in our study was estimated at $50 \%$, which was increased, this finding consistent with Abdallah and Ali [8]. Furthermore, the rate of completion of therapy remained unchanged in comparison to the number of cases and the death rate was also increased. A possible explanation is that even if patients kept their appointments and came to the hospital for prescription, many of them may not have actually taken the drugs. In the current NTP, there is no system of ensuring patients' compliance with self-administered drug therapy is clearly shown in this study, and the outcome of the treatment was not substantially improved. The infrastructure of the tuberculosis program in this state is not solid enough to the system work in a satisfactory manner.

It is a well-known fact that compliance with prescribed drugs is the most important sigh factor in the success of tuberculosis treatment program [14, 15]. Even if a patient attends hospital regularly; it is still uncertain whether he/she takes the prescribed medications. Consequently, drug resistance (particularly multi drug resistance) increases, which is another problem facing health planners [16]. The end result of this situation is a poor control of $\mathrm{TB}$ and a failure of the NTP to achieve its goals $[14,17]$. Long period hospitalization can solve some of the problems, but would be impractical and expensive. The retrieval system (phone, letters, home visit, etc.) can bring some patient to the 
hospital, but it would not be possible to guarantee that they take the prescribed drugs $[18,19]$. Other method like fixeddose combination may not prevent defaults. Twice or thrice weekly regimen makes it easier for patients to take medications, but patients who are not willing to continue treatment will nevertheless give up. Directly observed therapy short course (DOTS), which ensure that the patient actually take the medication under direct supervision of a nurse (or a heath assistant), has emerged after many years of dealing with the treatment method as probably the best solution to the problem of noncompliance, and has proven effective in various parts of the world [20-22]. A large Chinese study (112,842 patients) showed that with DOTS the failure rate dropped noticeably from $17.6 \%$ to $6.2 \%$ [23]. Furthermore, DOTS has been shown to be more costeffective in the longer term than the conventional methods of managing tuberculosis [24].

\section{Conclusion}

In the current setting of health services in Red Sea State, Sudan, the application of DOTS is only possible while patients are in the hospital. This would require long periods of admission, unfortunately Red Sea tuberculosis center hadn't awards for admission. We recommend that improvement of the essential and the infrastructure of the health care system would create a suitable environment to be a successful program.

\section{References}

[1] World Health Organization. World health reports the global tuberculosis epidemic. 2001; 233, P $1-2$.

[2] The World Factbook. [https://www.cia.gov/library/publications/the worldfactbook/index.html].

[3] Lewis MP, ed: Ethnologue: Languages of the World. Dallas, Texas SIL International; Sixteenth 2009.

[4] World Development Indicators database. [http://ddpext.worldbank.org/ext/ddpreports/ViewSharedRepo rt?

$\& \mathrm{CF}=\&$ REPORT ID $=9147 \&$ REQUEST $\quad$ TYPE $=$ VIEWADV ANCED].

[5] El-Sony AI, Khamis AH, Enarson DA, Baraka O, Mustafa SA, Bjune G: Treatment results of DOTS in 1797 Sudanese tuberculosis patients with or without HIV co-infection. Int J Tuberc Lung Dis 2002, 6 (12): 1058-1066.

[6] Stabler JM, Nicod L, Janssens JP, Extra pulmonary tuberculosis. Rev Mal Respir. 2012; 29 (4): 566 - 78.

[7] World Health Organization: Global tuberculosis control: WHO Report 2010. Geneva; 2010.

[8] Abdallah TM, Ali AA. Epidemiology of tuberculosis in eastern Sudan. Asian Pac J Trop Biomed. 2012; 2 (2): 999 1001 .
[9] Ali AA, Abdallah TM. Clinical presentation and epidemiology of female genital tuberculosis in eastern Sudanese. Int $\mathrm{J}$ Gyaencol Obstet. 2012; 1119 (3): 236 - 238.

[10] WHO Tuberculosis Programme. Framework for effective tuberculosis control. Genva, Switzerland: World Health Organization, 1994. World Health Organization Publication $\mathrm{WHO} / \mathrm{TB} / 94.179$.

[11] El-Sony AI: The cost to health services of human immunodeficiency virus (HIV) co-infection among tuberculosis patients in Sudan. Health Policy. 2006, 75 (3): 272-279.

[12] World Health Organization. Treatment of Tuberculosis: guideline. $4^{\text {th }}$ edition, WHO/HTM/TB/.2009. 420. 9789241547833 .

[13] Horsbergh CR, Barry CE, Lange C. Treatment of Tuberculosis. N Engl J Med, 2015; 373: 2149 - 60.

[14] Castelnuovo B. A review of Compliance to anti-tuberculosis treatment and risk factor for defaulting treatment in sub Saharan Africa. African Health Sciences. 2010; 10 (4): 320 323.

[15] Jin J, Sklar GE, Oh VM, Li SC. Factor affecting therapeutic compliance: A review from the patient's perspective. The Clin Risk Manag. 2008; 4 (1): 269 - 86.

[16] Al-Hajoj S, Varghese B, Shookri MM, Al-omari R et al. epidemiology of antituberculosis drug resistance in Saudi arabia: finding of the first national survey. Antimicrob Agents Chemother. 2013; 57 (5): 2161 - 66.

[17] Vijay S, Balasangameswara VH, Jagannatha PS, Saroja VN et al. Defaults among Tuberculosis patients treated Under DOTS in Bangalore city: A search for solution. Int. J Tub. 2003; 50: $185-95$.

[18] Thaim S, Lefevre AM, Hane F et al. Effectiveness of a stategy to improve Adherence to Tuberculosis Treatment in a Resource-Poor seting. JAMA. 2007; 297 (4): 367 - 379.

[19] Karumbi J, Garner P. Directly observed therapy for treating tuberculosis. Cochrane Database of systemic Reviews. 2015; issue 5 Art. No.: CD 003343.

[20] Moonan PK, Quitagua T, Pogoda J, Woo G et al. Does directly observed therapy (DOT) reduced drug resistance tuberculosis? BMC Public Health. 2011; 11: 19.

[21] De Queiroz EM, Guanito MC, Ferreira KR, Bertolozzi MR. Tuberculosis: limitations and strengths of directly observed treatment short-course. Rev. Latino Enfermagem, 2012; 20 (2): $369-77$.

[22] Ntshanga SP, Rustomijee R, Mabaso M. Evaluation of Directly Observed Therapy for tuberculosis in Kwazulu-Natal, South Africa. Trans R Soc Trop Med Hyg. 2009; 103 (6): 571 - 4.

[23] Result of directly observed short-course chemotherapy in 112,842 Chinese patients with smear-positive tuberculosis. China tuberculosis control collaboration. Lancet, 1996; 347: $358-62$.

[24] Meulemans H, Martelmans D, Liefooghe R, Mertens P et al. the limit to patient compliance with directly observed therapy for tuberculosis: a scocio-medical study in Pakistan. Int $J$ Health Plann Mgmt. 2002; 17: 249 - 267. 